\title{
Medical audit in a Scottish psychiatric service
}

\author{
George W. Fenton, Professor of Psychiatry; Brian R. Ballinger, Consultant \\ Psychiatrist; C. Barbara Ballinger, Consultant Psychiatrist; and Graham J. \\ NAYLOR, Reader in Psychiatry, Department of Psychiatry, University of Dundee, \\ Dundee DD1 9SY and Dundee Psychiatric Service
}

Psychiatry is unique in already being subject to statutory external audit through regular visits to psychiatric hospitals and units by the Hospital Advisory Services and Mental Health and Mental Welfare Commissions. These organisations do comment on aspects of the standard and quality of care. Reports of their findings undoubtedly facilitate change. By their programme of repeated visits they are in a position to observe the implementation and outcome of altered patterns of practice brought about by their reports. The Codes of Practice being prepared by the Mental Health Commission (England and Wales) and Mental Welfare Commission (Scotland) is another step that will significantly influence clinical practice. Finally, the Royal College of Psychiatrists' postgraduate training scheme accreditation exercise, like those of the other Royal Colleges and Faculties, has had an impact on quality of clinical care through its policy of gradually increasing the standard of postgraduate clinical training requirements. Locally based audit clearly complements these external exercises and local psychiatric services are now expected to organise systems of regular internal audit as are the other clinical disciplines (Department of Health, 1989).

The Dundee psychiatric service caters for an urban population of some 180,000 people and in addition provides out-patient and in-patient mental handicap care for the whole Tayside Region $(400,000)$. Audit activities have been in progress since the early 1970 s and have been slowly evolving over subsequent years. This paper reviews the Dundee experience as a contribution to the continuing national debate. A major facilitating factor was the establishment of a drug monitoring service for in-patient medication in 1970. This stimulated a series of studies of prescribing practice which were conducted in parallel with other investigations into the effects of various service changes. The drug monitoring exercise was quickly followed by the initiation of a system of routine collection of basic clinical data on all new referrals, which was recorded on a 'patient contact' form and stored in the Health Board computer. To formalise and extend the audit process, a medical audit subcommittee was set up in 1985 to review and facilitate developments in medical audit. The membership consists of four consultants (two NHS and two University), a senior registrar and a registrar representative. This committee is chaired by the Professor of Psychiatry, meets once a term and reports to the Dundee Division of the Psychiatric Executive Committee, of which it is a sub-committee.

The audit work carried out can be subdivided as follows:

\section{(1) Analysis of routinely collected health service data}

(a) In-patient and out-patient attendances Monthly tables of the numbers of in-patient admissions and discharges under the care of each consultant are circulated. More detailed information about the overall activity of the service is provided by an annual report, which is widely circulated. This includes comparative data from previous years and a commentary on any apparent trends.

(b) Drug monitoring service

Duplicates of the prescription sheet for each in-patient are collected and stored both manually and on computer as part of a routine drug information system for all inpatients. Every six months a computer printout displaying the distribution of the range of medication used by each ward is circulated. Included is information about the respective prices of each drug and a critical commentary about prescribing trends and practices.

Data from all in-patient prescription sheets used during the past 19 years are available and have provided the material for a number of surveys of medication practice over the years. The Drug Monitoring Unit also deals with day to day staff enquiries about medication and provides data about local practice for postgraduate education seminars on psychotropic drug treatment.

\section{(2) Clinical case review}

(a) Multidisciplinary case conferences The traditional case conference of selected patients is held once weekly and formal feedback on the six months outcome of each 
patient presented is given by the relevant consultant at a clinical audit meeting held at the end of the following term for all clinical staff. Developments under consideration are random selection of patients under the care of each consultant team for consideration at the clinical case conferences and six months' outcome review and random review of case notes. A pilot study using a computerised care plan for each patient will commence in the autumn.

(b) Accidents in hospital

A multidisciplinary 'clinical matters' group of consultants, senior nurses, administrators and members of related health care professions meet monthly in both the mental illness and mental handicap hospitals and conduct a review of all accidents in the hospitals and associated day hospitals.

\section{(3) Analysis of the effect of changes in service}

Over the years a series of Dundee projects have attempted to assess objectively the consequences of a number of changes in the service by analysing clinical data collected before and after the relevant change. These have included studies of the influence of opening a new geriatric psychiatry day hospital on waiting lists for in-patient care, and the opening of an acute general psychiatric day hospital for acute in-patient admission numbers. The effects of the transfer of long stay dementia patients to a new purpose built ward block of standard design on behaviour, accident frequency and medication use have also been studied as well as the consequences of reducing bed numbers per ward for this type of patient. Similar studies have examined the effect of creating mixed sex wards in the mental handicap hospital, the influence of higher nurse-patient ratios on the recreational activities of mentally handicapped inpatients and of introducing voluntary workers into a geriatric psychiatry day hospital. A sociological observational investigation of the effects of the de-institutionalisation of a ward of mentally handicapped patients has been completed recently. Projects in the planning stage include studies of the impact on the service of the opening of a new day hospital for the severely mentally handicapped and the effect of recently implemented community care initiatives on the psychiatric rehabilitation programme.

\section{(4) Analysis of the current functioning of selected sectors of the psychiatric service}

The work of the lithium clinic, the psychiatric rehabilitation unit and the assessment clinic, which provides an emergency psychiatric assessment facility for the City of Dundee, have all been the subject of analysis and presentation to multidisciplinary meetings of members of the psychiatric service. To facilitate the data retrieval and analysis process, microcomputers have been introduced into the Lithium and Drug Problems Clinics and Rehabilitation Unit. A locally developed menu driven software system ('CRAFT'), designed as an aid to medical audit and patient management is available for use (Walker et al, 1988).

\section{(5) Analyses of appropriate use of investigations and therapies}

An early audit exercise assessed the value of the routine physical investigation of acute in-patient admissions. The reasons for the referral of patients for EEG investigation by Dundee psychiatrists have recently been examined and the consequent clinical value of such recordings assessed. In the therapeutic arena, an interesting project has been an evaluation of the relative contributions of out-patient psychiatric care and day hospital management to the outcome of patients with chronic neurotic illness. A current project comparing the effectiveness of short term dynamic psychotherapy with cognitive therapy in patients with generalised anxiety disorder is under way.

\section{(6) Postgraduate education}

A handbook containing information about the psychiatric and mental handicap service and guidelines about performance of standard tasks and treatments, e.g. ECT and advice on referral to the various specialised services, is provided for each member of the psychiatric staff. This includes a section of guidance on special investigations in psychiatry. This is reviewed at regular intervals by the medical audit sub-committee, updated and expanded when appropriate.

During the weekly postgraduate teaching programme at least one session a term is devoted to a presentation on a topic considered to require special attention to improve the standard of clinical practice. These are carried out by either members of the Dundee Psychiatric Service or invited external specialists.

\section{(7) Patients' attitudes towards the care provided}

Although mentally ill and handicapped patients may experience difficulty in assessing the technical efficiency of care and treatment, their views and those of their relations as consumers of the service are an important dimension to audit, largely neglected during the present debate despite the title of the government White Paper. Surveys of their views of treatment, staff helpfulness and wishes for future placement were carried out in the early seventies. A project to sample routinely the opinions of all inpatients about the standards of accommodation and 


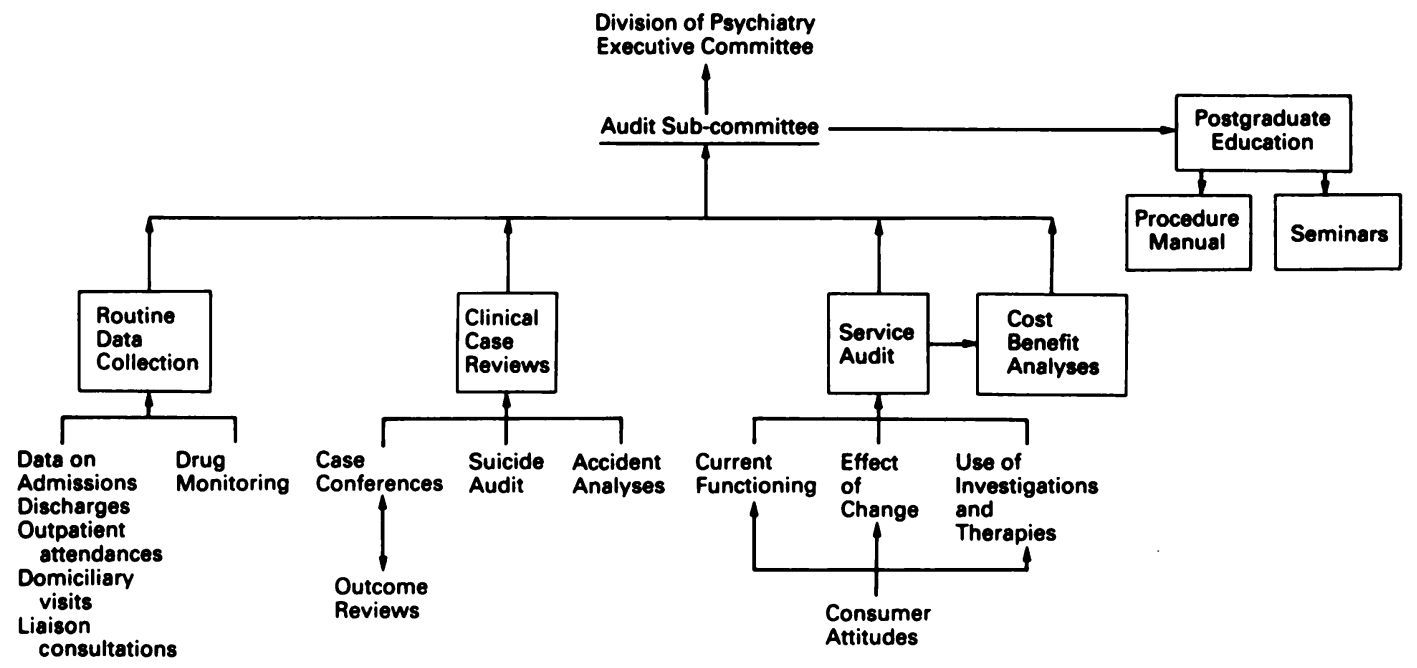

FIG. 1. Medical audit process

care is due to be implemented in the near future. The collection of criteria that measure the quality of life of patients both in hospital and living in the community is clearly of the utmost importance.

\section{(8) Cost-efiectiveness in financial terms}

In the current climate of cash limits and resource constraints the application of medical audit to the issue of cost effectiveness in the delivery of care is attractive. Audit may identify areas where savings may be made without adversely affecting quality of care. Our audit programme provides guidelines on the use of special investigations and a standard drug formulary, both of which have the potential to produce savings. However, we have not attempted to assess the cost effectiveness of these exercises. The only audit project that examined cost was the comparative study of conventional out-patient $v$. day hospital treatment for chronic neurotic patients. Day hospital management resulted in a significantly better clinical outcome but was more expensive in terms of cost.

\section{Comment}

The process of medical audit in the Dundee Psychiatric Service has evolved gradually over the past two decades, starting initially with therapeutic drug monitoring and expanding on an ad hoc basis since then. Four years ago, it became formalised by the setting up of a sub-committee to act as a forum to encourage and monitor the process. Despite its apparently random evolution, it is possible to discern an emerging pattern that will provide the framework for future development (Fig. 1). This is not dissimi- lar to that described by McKee et al (1989). There appear to be four main pillars to the process, namely the analyses of routinely collected data, clinical case reviews, audit of services and cost benefit analysis projects, while the postgraduate education programme provides an ideal forum for feedback and discussion of the audit that is essential if audit exercises are to benefit clinical care at grassroots level.

The other essential avenue of output is by way of the NHS administrative system. By reporting directly to the Division of Psychiatry and hence to the Unit Management Team, the audit sub-committee bring the audit findings to the attention of the administrators and managers. Doubtless this output process will in the near future be continued into the Area Health Board Audit Committee and hence to the National Audit Committee of the Scottish Home and Health Department (Workshop on Medical Audit, 1989). The role of the Scottish Division of the Royal College of Psychiatrists in the audit process is clearly an important one, especially for facilitating and coordinating nationwide audit exercises. The Child and Adolescent Psychiatry Section already has a pilot project under way looking at performance indicators in child psychiatry services across Scotland and a working party is currently examining ways of co-ordinating audit in adult psychiatry.

To return to the four main pillars of our local strategy, the left hand side of the flow diagram, namely the routine data collection and clinical case reviews, are well established operations that will be easy to continue using present resources. Expansion of the data collection programme is feasible by the operation of a user friendly computer database system, the provision of staff training facilities to prepare and 
support the people using it and the funding of a modest increase in administrative staffing at senior clerical officer level. Audit of specific aspects of the service with or without cost benefit analysis is a much more formidable undertaking. Where data other than that collected routinely are required, a substantial commitment of staff time is needed and has only been possible through the help of a sabbatical visitor to the Department of Psychiatry, a considerable amount of senior registrar/consultant time usually involving much out of hours work or the assistance of research workers funded by external grants.

Perhaps the necessary expansion in staff time to complete specific audit projects can be provided by a collaborative effort of local and national initiatives. At local level, the unit of management will have to budget for sufficient funding to provide a small audit team to give administrative and technical support for staff members carrying out audit exercises, namely a full time clerical officer and a graduate in information technology or related discipline of Scientific Officer status. The local postgraduate education programme will have to make the performance of an audit exercise a mandatory part of the postgraduate training of all registrars and senior registrars; one audit project using routinely collected data at registrar level and a more complex one during higher psychiatric training.

Consultant supervision is essential and we estimate that our service requires a minimum of two consultant sessions a week for medical audit (one consultant session per 100,000 population). An ideal number to aim for is one session a week per consultant in post.

At national level, the College can play a crucial role by requiring participation in audit to be a mandatory part of postgraduate psychiatric training. Government has an equally important contribution. Modern cost-conscious governments are unlikely to provide sufficient additional funds to establish the manpower necessary to make regular complex service audit projects feasible in every unit throughout the land. Perhaps the most efficient use of the meagre resources available is for the Department. of Health and Scottish Home and Health Department to establish a programme of short term grants of one to three years duration to support specific audit projects using the model of the Chief Scientists' Organisation, that works so well in supporting biomedical and health services related research. Finally, the editors of psychiatric journals can help by encouraging the publication of important and well executed audit projects. There may be a case for establishing a journal of medical audit. Indeed, the list of publications of the Dundee audit studies demonstrates that medical audit can be a fruitful area of clinical research (publication list available on request).

In conclusion, we regard our Dundee experience as only a modest beginning to a complex and formidable task that must evolve over the years to include the work of the other health care disciplines related to psychiatry and community care projects as well as to the development of tools to monitor both the process and outcome of care, based on research evidence linking the two and on agreed clinical protocols, as suggested by Shaw (1989) for internal medicine. Similarly, methods for sampling consumer opinion of the services offered will have to be developed and refined through surveys of the attitudes of patients, their carers and the general public.

\section{Acknowledgement}

We wish to thank our psychiatric colleagues, administrative staff and members of the other health care disciplines without whose active participation and support this audit work would have been impossible.

\section{References}

Department of Health (1989) Working for Patients. London: HMSO.

McKee, C. M., LANGLo, M. \& Lessof L. (1989) Medical audit: a review. Journal of the Royal Society of Medicine, 82, 474-478.

SCOttish Home and Health Department (1989) Workshop on Medical Audit, 27 April 1989.

SHAw, C. D. (1989) Audit in internal medicine. British Journal of Hospital Medicine, 42, 19.

WALKER, M. A., BryCE, D. \& CARTER, N. W. (1988) Craft: an aid to medical audit research and patient management. Health Bulletin, 46, 42-54. 